\title{
BMJ Open Workplace violence against healthcare professionals in a multiethnic area: a cross-sectional study in southwest China
}

Haonan Jia (D) , ${ }^{1,2}$ Huiying Fang, ${ }^{3}$ Ruohui Chen, ${ }^{2,4}$ Mingli Jiao ${ }^{(1)},{ }^{2,5}$ Lifeng Wei,
Gangyu Zhang, ${ }^{2}$ Yuanheng Li, ${ }^{2}$ Ying Wang, ${ }^{2}$ Yameng Wang, ${ }^{2}$ Kexin Jiang, ${ }^{6}$
Jingqun Li, ${ }^{7}$ Xiaowen Jia, ${ }^{8}$ Omar Yacouba Ismael, ${ }^{2}$ Jingfu Mao, ${ }^{9}$ Qunhong Wu ${ }^{10}$
To cite: Jia $\mathrm{H}$, Fang $\mathrm{H}$, Chen R, et al. Workplace violence against healthcare professionals in a multiethnic area: a cross-sectional study in southwest China. BMJ Open 2020;10:e037464. doi:10.1136/ bmjopen-2020-037464

- Prepublication history for this paper is available online. To view these files, please visit the journal online (http://dx.doi. org/10.1136/bmjopen-2020037464).

$\mathrm{HJ}, \mathrm{HF}$ and $\mathrm{RC}$ contributed equally.

Received 04 February 2020 Revised 27 June 2020 Accepted 02 July 2020

Check for updates

(c) Author(s) (or their employer(s)) 2020. Re-use permitted under CC BY-NC. No commercial re-use. See rights and permissions. Published by BMJ.

For numbered affiliations see end of article.

Correspondence to

Dr Mingli Jiao;

minglijiao@126.com

\section{ABSTRACT}

Objective The purpose of this study is to examine workplace violence (WPV) towards healthcare professionals in a multiethnic area in China, including prevalence, influencing factors, healthcare professionals' response to WPV, expected antiviolence training measures and content, and evaluation of WPV interventions.

Design A cross-sectional study.

Setting A grade III, class A hospital in the capital of Yunnan Province, which is the province with the most diverse ethnic minority groups in China.

Participants In total, 2036 healthcare professionals participated, with a response rate of $83.79 \%$.

Results The prevalence of physical and psychological violence was $5.5 \%$ and $43.7 \%$, respectively. Healthcare professionals of ethnic minority were more likely to experience psychological violence $(\mathrm{OR}=1.54,95 \% \mathrm{Cl}$ 1.16 to 2.05). Stratified by gender, male healthcare professionals of ethnic minority suffered from more physical violence (OR=3.31, 95\% $\mathrm{Cl} 1.12$ to 9.79$)$, while female healthcare professionals suffered from psychological violence ( $\mathrm{OR}=1.71,95 \% \mathrm{Cl} 1.24$ to 2.36). We also found a unique work situation in China: overtime duty on-call work (18:00-07:00) was a risk factor for psychological violence $(\mathrm{OR}=1.40,95 \% \mathrm{Cl} 1.02$ to 1.93$)$. Healthcare professionals of ethnic minority are less likely to order perpetrators to stop or to report to superiors when faced with psychological violence. They are also more interested in receiving training in force skills and self-defence. Both Han and ethnic minority participants considered security measures as the most useful intervention, while changing the time of shift the most useless one.

Conclusion Our study comprehensively described WPV towards healthcare professionals in a multiethnic minority area. More research on WPV conducted in multiethnic areas is needed.

\section{INTRODUCTION}

In December 2019, a doctor was brutally killed by a patient's family member in Beijing. Less than a month later, another doctor in a Beijing hospital was stabbed and severely injured. These two cases once again drew great attention to the safety of healthcare professionals in the Chinese society.
Strengths and limitations of this study

- Although a lot of studies have investigated workplace violence (WPV) in hospitals, few were conducted in multiethnic minority areas.

- Previous studies paid attention to a single aspect of WPV, whereas our study describes WPV comprehensively including prevalence, influencing factors and response to WPV.

- Due to recall bias or reporting bias resulting from shame and stigma, the number of violent events in the past 12 months may be underestimated.

- Our study did not explain WPV using cultural factors, which further studies can investigate.

Workplace violence (WPV) is defined as 'incidents where employees are abused, threatened, assaulted or subject to other offensive acts or behaviors in circumstances related to their work'. It includes two types: (1) physical violence (eg, beating, kicking, slapping, stabbing, shooting, pushing, biting and pinching) and (2) psychological violence (eg, threat of physical force against another person or group that can result in harm to physical, mental, spiritual, moral or social development). ${ }^{1}$ WPV towards healthcare professionals is an extremely serious problem in China and has been happening for a long time. From 2000 to 2015, the media reported less than 290 cases of severe WPV towards healthcare workers. ${ }^{2}$ The seriousness of WPV towards healthcare professionals in China has attracted great attention from researchers. Most of the research that studied the prevalence of WPV in China were conducted in areas where the Han people (the main ethnic group in China) mainly live and the rates of physical and psychological violence were $6.4 \%-35.4 \%$ and $54.4 \%-79.8 \%$, respectively. ${ }^{3-8}$ However, there are few WPV studies conducted in the multiethnic areas of China. According to the latest national census in 
2010, ethnic minorities account for $8.49 \%$ of the total population in China. In multiethnic areas, the proportion and ethnic diversity of both ethnic minority patients and healthcare professionals are higher. In addition, there is preferential treatment policy in education for Chinese ethnic minorities (lower threshold to receive high level of education), which may make ethnic minority workers' capabilities undervalued. ${ }^{9}{ }^{10}$ However, since healthcare professionals require high level of skills and education, it remains unknown whether ethnic minority healthcare professionals' ability and skills would be undervalued and can lead to patients' distrust with even more WPV occurrence. It is essential to provide more data on WPV in a multiethnic area in order to conduct specific interventions. In addition, there are limited studies from other countries and regions that focus on WPV towards healthcare professionals in multiethnic areas.

Although many studies have investigated the influencing factor for WPV towards healthcare professionals, an essential factor has been neglected. In China, more than $90 \%$ of healthcare professionals work more than 8 hours a day, which makes overtime work a common phenomenon. ${ }^{11}$ Since the medical system requires healthcare professionals to be responsible for their patients at any time, duty on-call has become a form of overtime work. Healthcare workers need to be on a 24-hour stand-by and be able to return to the hospital to attend to patients in acute or severe situations, even when they have already got off work or are taking a rest. ${ }^{12}$ Previous studies found that workload was associated with WPV victimisation. ${ }^{13} 14$ However, there are limited WPV studies that focused on the relationship between WPV experience and the exact form of overtime.

Most previous WPV studies have only investigated an aspect of WPV, such as prevalence, influencing factors or interventions. In this study, we aim to investigate WPV in a general hospital of a multiethnic area, including the prevalence, influencing factors, response to WPV and evaluation of WPV intervention, which could allow not only interpretation of WPV from a broader perspective, but also provide more reference for practice.

\section{METHODS}

\section{Study population}

Yunnan, located in the southwestern border of China, has the most diverse ethnic minorities in the country, with 52 of 56 ethnic groups (51 ethnic minority groups and Han). In $2017,33.6 \%$ of residents in Yunnan belonged to ethnic minority groups.

We conducted a retrospective survey in a grade III, class A hospital in Kunming, the capital of Yunnan Province. The hospital was founded in 1939 and is the first grade III, class A hospital in Yunnan Province. It is one of the most capable general hospitals in Yunnan, with 2400 open beds and over 2 million total visits annually. Around $18.6 \%$ of the hospital's employees were of ethnic minority at the time of the study. As a medical centre in the province, it has a wide radiation range, and patients from all over the province come to this hospital to seek medical treatment.

\section{Questionnaire}

A questionnaire developed jointly by the International Labour Office (ILO), International Council of Nurses, WHO and Public Services International in 2003 was used to measure WPV. ${ }^{1}$ First, we asked for permission to use the questionnaire from the ILO and WHO. Thereafter, we translated it into Mandarin Chinese and back-translated it into English to verify the accuracy of the Mandarin version. After this translation process, 17 experts in the field of healthcare were invited to assess the effectiveness of the measurement tools, including the applicability of culture and the appropriateness of language. We selected 79 medical staff to form a group and conducted a 2-week test-retest reliability test $(0.83)$.

The questionnaire included the following sections: (1) demographics (eg, gender, age, education, ethnicity, occupation) and work status (eg, shift work, overtime duty on-call work, participation in antiviolence training, anxiety towards WPV); (2) experience of physical violence in the past 12 months (ie, intentional behaviour that harms healthcare workers physically); (3) experience of psychological violence in the past 12 months (ie, verbal abuse, threatening events and sexual harassment); (4) healthcare professionals' response to physical violence and psychological violence; (5) the expected measures (eg, leaflets, video, lecture) and content of antiviolence training (eg, WPV cognition, self-defence); and (6) the evaluation of usefulness of WPV interventions.

\section{Sample and data collection}

First, we obtained permission from the hospital management office and human resource department to collect hospital employees' information. Thereafter, the person in charge of each unit issued a questionnaire to the staff and informed them of the instructions and precautions. The study subjects included doctors, nurses and medical technicians, who participated voluntarily and remained anonymous.

The respondents were asked to provide their experience of WPV in the previous 12 months. We excluded employees who met any of the following criteria: (1) less than 1 year of work experience in the hospital; (2) shortterm secondment or training (less than 12 months); and (3) personnel who did not come to work during the study period due to travel, training, vacation and so on.

The questionnaire had to be completed by the employees themselves and could not be answered by any other person. The time of data collection ranged from July to October 2017. A total of 2036 valid questionnaires were collected, and the effective response rate was $83.79 \%$.

\section{Data analysis}

Descriptive statistics were used to summarise the demographic characteristics, prevalence of physical and 
psychological violence, and the response to WPV between Han and ethnic minority participants. $\chi^{2}$ test and Fisher's exact test were used to compare the difference in response to WPV between Han and ethnic minority healthcare workers.

Since ethnic minority participants were almost one-fifth of Han participants in our data collection, the result may be biased if we used the original data to conduct logistic regression. To control confounders and to balance the number of Han and ethnic minority samples, propensity score matching (PSM) was used. The PSM model used ethnicity as the dependent variable, and age, gender, marriage status, educational background and years of work experience as explanatory variables. We matched the group of ethnic minority healthcare professionals (treatment group) to the group of Han healthcare professionals (control group) in a 1:2 manner to create two groups. These two groups had similar explanatory variables (age, gender, marriage status, educational background, years of work experience) and different dependent variable, ethnicity, which could control confounders and highlighted the comparison between Han and ethnic minority healthcare professionals. After matching, a set of 960 cases were created, with 325 ethnic minority and 635 Han healthcare professionals. The matched set was used to identify the factors associated with WPV in hospitals using logistic regression. Since the proportion of male and female was almost 1:3, we also conducted logistic regression stratified by gender.

The data were entered using EpiData V.3.1 and analysed using IBM SPSS Statistics V.22.0. The significance level was set at 0.05 .

All respondents provided informed consent, and were informed of the purpose and method of data collection and that the data will be kept confidential.

\section{Patient and public involvement}

No patients were involved in the whole research process.

\section{RESULTS \\ Demographic characteristics}

Table 1 shows the demographic details of the 509 men and 1527 women who participated in the study. Around $84 \%$ of the respondents were of 'Han ethnicity', while $16 \%$ were of ethnic minority. Majority of the respondents were nurses $(42.7 \%)$ and physicians (30.6\%), $14.4 \%$ were medical technology workers, and the rest $(12.3 \%)$ held other positions. Most of the respondents $(70.2 \%)$ worked in rotational shifts, and $74.2 \%$ engaged in overtime work (from 18:00 to 07:00 the next day), such as overtime or emergency consultation. Over half reported high or extremely high levels of anxiety towards WPV (58.9\%) and participated in antiviolence training $(67.5 \%)$. As for the prevalence of WPV, $43.7 \%$ of the respondents reported that they had experienced psychological violence, while $5.4 \%$ reported physical violence.
Table 1 Demographic information and the prevalence of workplace violence $(\mathrm{N}=2036)$

\begin{tabular}{|c|c|c|}
\hline & $n$ & $\%$ \\
\hline \multicolumn{3}{|l|}{ Gender } \\
\hline Male & 509 & 25.0 \\
\hline Female & 1527 & 75.0 \\
\hline \multicolumn{3}{|l|}{ Age } \\
\hline$\leq 30$ & 940 & 46.2 \\
\hline $31-45$ & 789 & 38.8 \\
\hline$\geq 46$ & 307 & 15.0 \\
\hline
\end{tabular}

Marital status

\begin{tabular}{lrr} 
Single & 603 & 29.6 \\
Married & 1389 & 68.2 \\
\hline Divorced/widowed & 44 & 2.2 \\
\hline
\end{tabular}

Educational background

\begin{tabular}{lrr} 
College graduates & 448 & 22.0 \\
\hline Bachelor's degree & 1207 & 59.3 \\
\hline $\begin{array}{l}\text { Master's degree and above } \\
\text { Ethnicity }\end{array}$ & 381 & 18.7 \\
$\quad$ Han & 1711 & 84.0 \\
$\quad$ Minority & 325 & 16.0 \\
$\begin{array}{l}\text { Years of work experience } \\
\text { 1-5 }\end{array}$ & \\
$6-10$ & 570 & 28.0 \\
\hline $11-20$ & 548 & 26.9 \\
$>20$ & 413 & 20.3 \\
\hline
\end{tabular}

Profession

\begin{tabular}{lcc} 
Physician & 624 & 30.6 \\
\hline Nurse & 869 & 42.7 \\
\hline Medical technology & 294 & 14.4 \\
Others & 249 & 12.3 \\
Work in shift & & \\
$\quad$ Yes & 1429 & 70.2 \\
$\quad$ No & 607 & 29.8 \\
Overtime duty on-call work (18:00-07:00) & \\
Yes & 1510 & 74.2 \\
$\quad$ No & 526 & 25.8 \\
Anxiety level & & \\
$\quad$ Never & 103 & 5.1 \\
$\quad$ Low & 219 & 10.8 \\
$\quad$ Moderate & 513 & 25.2 \\
$\quad$ High & 360 & 17.7 \\
$\quad$ Extremely high & 841 & 41.2 \\
Antiviolence training & & \\
Yes & 1374 & 67.5 \\
$\quad$ No & 662 & 32.5 \\
\hline Physical violence &
\end{tabular}

Continued 


\begin{tabular}{lrr}
\hline Table 1 & Continued & \\
\hline & $\mathbf{n}$ & $\%$ \\
\hline Yes & 110 & 5.5 \\
No & 1926 & 94.5 \\
Psychological violence & & \\
Yes & 889 & 43.7 \\
No & 1147 & 56.3 \\
\hline
\end{tabular}

\section{Influencing factors}

Table 2 shows the results of the logistic regression analysis of physical and psychological violence using the matched set (unstratified and stratified by gender), including $\mathrm{p}$ values, OR and 95\% CI. The unstratified results showed that female respondents had lower odds of experiencing physical violence than male respondents $(\mathrm{OR}=0.29,95 \%$ CI 0.15 to 0.55$)$. Respondents with anxiety level towards WPV had higher odds of physical violence ( $\mathrm{OR}=1.88,95 \%$ CI 1.34 to 2.62 ). Stratified by gender, the results showed that an educational background of master's degree and above $(\mathrm{OR}=7.49,95 \%$ CI 1.27 to 44.04$)$, ethnic minority $(\mathrm{OR}=3.31,95 \%$ CI 1.12 to 9.79$)$ and anxiety level towards WPV (OR=2.46, 95\% CI 1.35 to 4.48$)$ were associated with the occurrence of physical violence among men, while only anxiety level towards WPV (OR=1.84, 95\% CI 1.17 to 2.88) was statistically significant with experience of physical violence among women.

As for psychological violence, minority medical workers had higher odds of experiencing it than workers of Han ethnicity ( $\mathrm{OR}=1.54,95 \%$ CI 1.16 to 2.05$)$. Engaging in overtime work from 18:00 to 07:00 the following day was also a risk factor for psychological violence $(\mathrm{OR}=1.40,95 \%$ CI 1.02 to 1.93 ). Anxiety level about WPV was also negatively associated with psychological violence $(\mathrm{OR}=1.50$, $95 \%$ CI 1.33 to 1.70$)$. When stratified by gender, women of ethnic minority ( $\mathrm{OR}=1.71,95 \%$ CI 1.24 to 2.36$)$ were more likely to suffer from psychological violence, while antiviolence training ( $\mathrm{OR}=0.71,95 \%$ CI 0.51 to 0.99 ) was positively associated with psychological violence; both men $(\mathrm{OR}=1.48,95 \%$ CI 1.14 to 1.92$)$ and women $(\mathrm{OR}=1.51,95 \% \mathrm{CI} 1.31$ to 1.74$)$ with higher anxiety levels towards WPV were associated with WPV victimisation.

\section{Participants' response to WPV}

Table 3 shows the different responses to psychological/ physical violence between Han and ethnic minority healthcare professionals. More Han healthcare professionals ordered perpetrators to stop $(\mathrm{OR}=0.64,95 \% \mathrm{CI}$ 0.45 to 0.91 ) and reported to superiors $(\mathrm{OR}=0.56,95 \%$ CI 0.40 to 0.79 ) than ethnic minorities when psychological violence happened, and this difference was statistically significant. As for physical violence, compared with ethnic minority, more Han healthcare professionals chose to respond in all ways except pretending like nothing happened. However, none of the differences was statistically significant.

\section{Antiviolence training measures and content}

Table 4 shows the antiviolence training measures and content expected by healthcare professionals. Lectures were the most expected measures of training both by Han $(54.12 \%)$ and those of ethnic minority $(52.62 \%)$. Pre-job training was expected by half of ethnic minority healthcare professionals, which was slightly higher than the proportion of Han healthcare professionals ( $\mathrm{OR}=1.29$, 95\% CI 1.01 to 1.63). Wall newspaper and poster were the least popular measures both among Han and ethnic minorities. As for the training content, more than $70 \%$ of Han and ethnic minority participants expected identification of WPV signs and escaping training. Compared with Han, ethnic minority healthcare professionals were more interested in force skills $(\mathrm{OR}=1.40,95 \%$ CI 1.10 to 1.78$)$ and self-defence ( $\mathrm{OR}=1.48,95 \%$ CI 1.10 to 2.01).

\section{Evaluation of the usefulness of WPV interventions}

As for the evaluation of interventions, there were no significant differences between Han and ethnic minority healthcare professionals. Participants considered that security measures were the most useful ways to prevent WPV, followed by improving the environment and antiviolence training. More than $40 \%$ considered patient examination and changing the time of shift as useless measures. There were few differences when stratified by ethnicity. More Han healthcare workers looked down on the usefulness of protective equipment, while ethnic minority participants undervalued patient examination and antiviolence training. However, none of these differences between Han and ethnic minority was statistically significant (table 5).

\section{DISCUSSION}

This study examined the prevalence, influencing factors and response to WPV in a hospital located in a multiethnic area in China. The percentage of medical workers of ethnic minority was substantially higher than previous studies conducted in eastern and central China $(2.41 \%-$ $7.95 \%) .{ }^{15-17}$ Due to the different investigation tools and time period, it is difficult to compare the WPV prevalence with some other research. However, compared with our previous studies with the same questionnaire and time period, the prevalence of physical and psychological violence in our study is lower than what has been found in areas where Han people mainly lived. ${ }^{781819}$ The results of logistic regression indicated that ethnic minority healthcare professionals may be more likely to suffer from psychological violence. Stratified by gender, men of ethnic minority were more likely to suffer from physical violence, while women from psychological violence. The different results obtained from stratified and unstratified analyses may be due to the proportion of men and women. Namely, in unstratified analysis, the fact that men suffered from more physical violence would be covered by the fact that women suffered from more psychological violence. Some studies from other countries or regions 


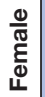

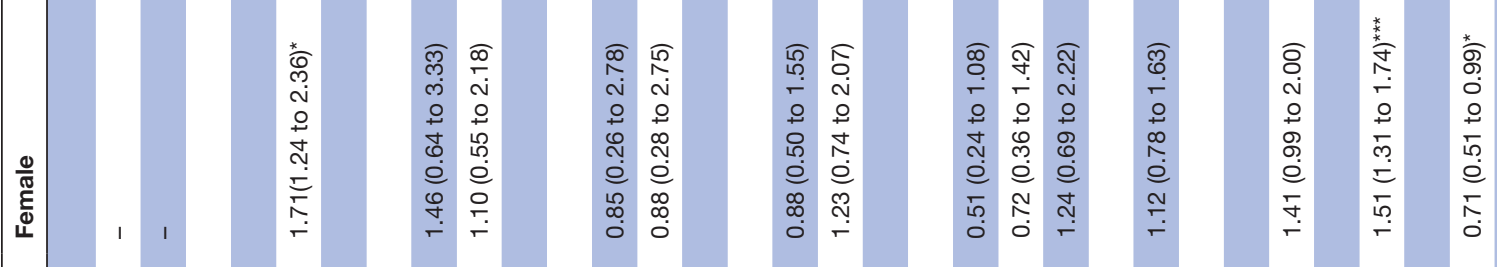

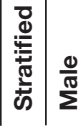

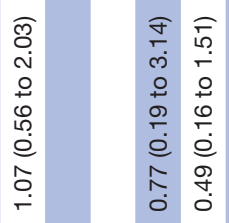

\ֶ.





กิ่

:

每

우 웅

อ

$\begin{array}{ll}10 & \infty \\ 0 & 0 \\ 0 & 0\end{array}$



$\begin{array}{lll}0 & 0 & 0 \\ 0 & 0 & 0 \\ 0 & 0 & 0\end{array}$

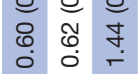

总



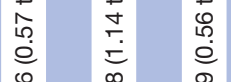

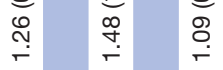

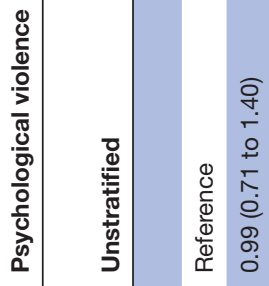

盖

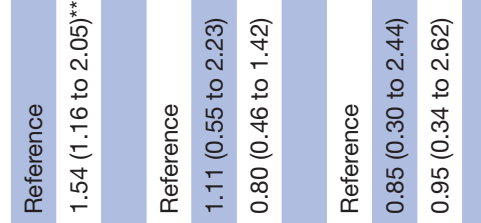

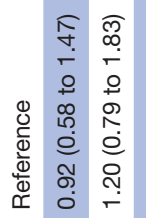

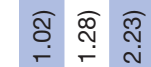

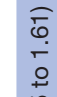

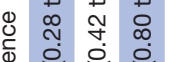

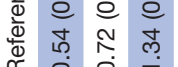

2 .



$\frac{1}{8}$

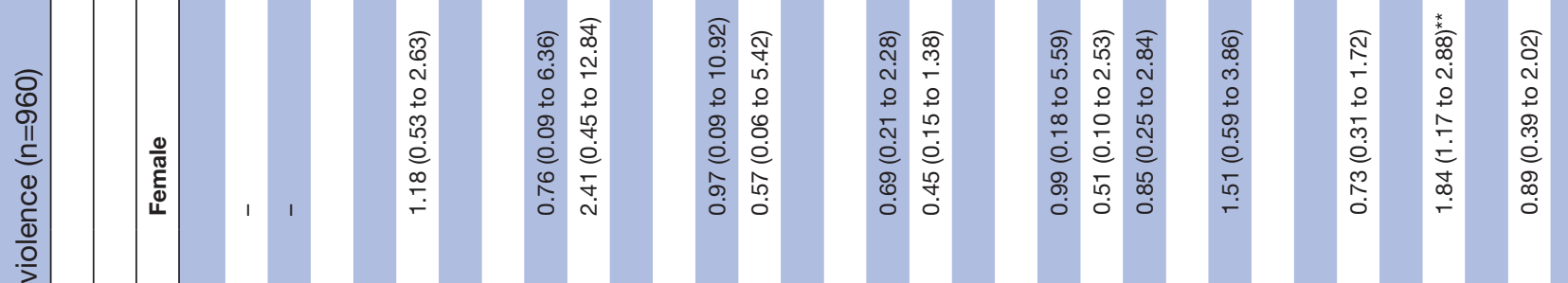

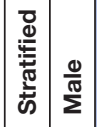

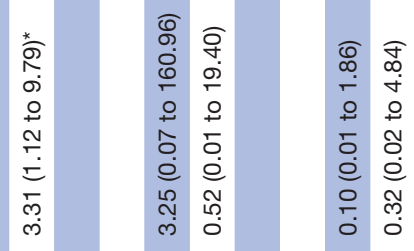



凹్ల

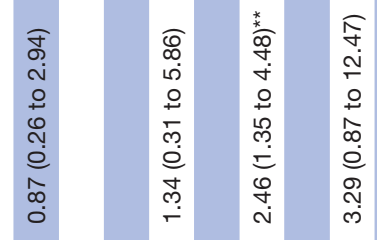

타

న్

ले

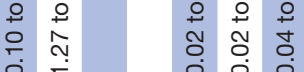

o

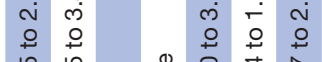

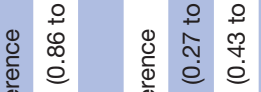

ก

-

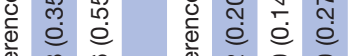

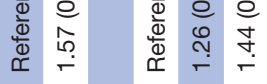

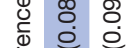

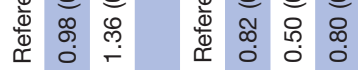

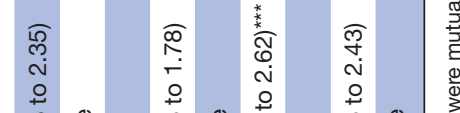

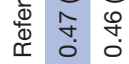



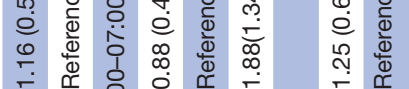

$\stackrel{0}{\mathbb{D}}$ 


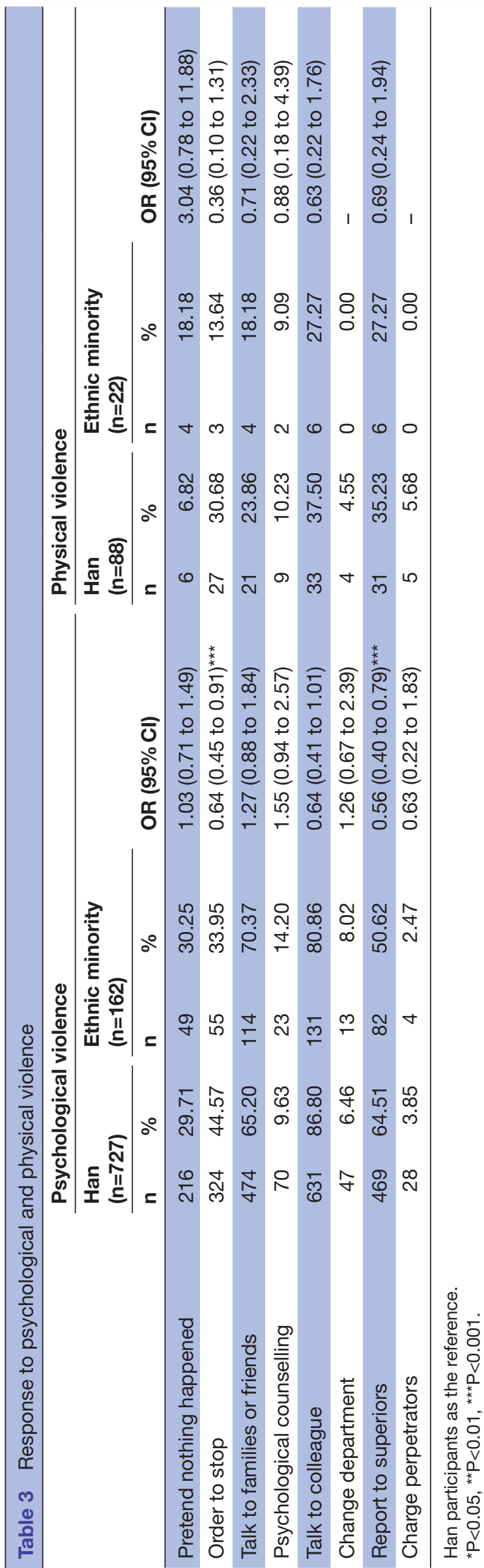

showed that ethnic minority healthcare workers were less likely to experience WPV when compared with the majority (whites), ${ }^{20} 21$ while some studies held the opposite conclusion that ethnic minority healthcare professionals were more vulnerable to workplace bullying, verbal abuse, physical violence and so on. ${ }^{22-26}$ However, due to the huge differences between the background investigation and participants' characteristics, these studies could not be compared with our study. We speculate several reasons for this result. First, our study showed that there were behavioural differences between Han and ethnic minority; culture and religious beliefs could be key factors in explaining this. ${ }^{27}$ Second, our study showed that when faced with WPV, compared with Han, ethnic minority healthcare professionals may be more likely to tolerate it, which may lead to more violence. Third, differences in linguistic culture may hamper the doctor-patient communication and thus lead to violence. ${ }^{28}$ Fourth, ethnic minority healthcare professionals' ability or skills may be undervalued by patients, leading to distrust or to WPV. Further studies that investigate this phenomenon from the patient's perspective are needed.

Respondents who engaged in overtime duty on-call work from 18:00 to 07:00 are at greater odds of experiencing psychological violence. This is a new finding in our study and has been ignored in most research in China. We speculate several reasons for this finding. First, our definition of overtime duty on-call work might have captured individuals handling urgent issues. The staff working therein are more likely to experience higher levels of frustration, distress, cognitive impairment or arousal, ${ }^{29}{ }^{30}$ which is similar with the WPV high-risk department-emergency department. Second, healthcare professionals would face more aggressive situations such as drunk patients or companions and traumatic patients due to fighting. Third, since the on-call work is not during the regular working time, there are fewer colleagues and guards. We suggest that more effective measures be adopted to protect healthcare professionals who engage duty on-call beyond their regular working time. Future studies should investigate this phenomenon in areas where Han people mainly live.

The results of logistic regression showed that men are at higher odds of experiencing physical violence, which is similar to the WPV studies conducted in areas where Han mainly lived. ${ }^{71931}$ In other countries, some studies came up with the same conclusion, ${ }^{32-35}$ while some studies have reported that women were more vulnerable to physical violence. ${ }^{36}$ These different results could be attributed to the different study backgrounds. ${ }^{37}$ In many countries, beliefs, ethics or moral principles serve as guidance for public behaviour. For instance, in some Arab countries, being a male is a risk factor for experiencing WPV partly due to cultural norms that reject disrespect of women. ${ }^{35}$ Consistent with other research ${ }^{719}$ conducted in areas where Han mainly live, our study showed that higher level of anxiety towards WPV was associated with WPV experience. Further study should determine whether the 
Table 4 Expected measures and content of antiviolence training ( $N=2036)$

\begin{tabular}{|c|c|c|c|c|c|}
\hline & \multicolumn{2}{|c|}{$\operatorname{Han}(n=1711)$} & \multicolumn{2}{|c|}{ Ethnic minority $(n=325)$} & \multirow[b]{2}{*}{ OR $(95 \% \mathrm{Cl})$} \\
\hline & $\mathbf{n}$ & $\%$ & $\mathbf{n}$ & $\%$ & \\
\hline \multicolumn{6}{|c|}{ Expected training measures } \\
\hline Video & 759 & 44.36 & 145 & 44.62 & $1.01(0.80$ to 1.28$)$ \\
\hline Lectures & 926 & 54.12 & 171 & 52.62 & $0.94(0.74$ to 1.19$)$ \\
\hline $\begin{array}{l}\text { Employee } \\
\text { handbooks }\end{array}$ & 507 & 29.63 & 93 & 28.62 & $0.95(0.73$ to 1.24$)$ \\
\hline Pre-job training & 751 & 43.89 & 163 & 50.15 & $1.29(1.01 \text { to } 1.63)^{*}$ \\
\hline \multicolumn{6}{|c|}{ Expected training content } \\
\hline Language skills & 1162 & 67.91 & 232 & 71.38 & $1.18(0.91$ to 1.53$)$ \\
\hline Force skills & 815 & 47.63 & 182 & 56.00 & $1.40(1.10 \text { to } 1.78)^{\star \star}$ \\
\hline $\begin{array}{l}\text { Relevant laws and } \\
\text { regulations }\end{array}$ & 1113 & 65.05 & 223 & 68.62 & 1.18 (0.91 to 1.52$)$ \\
\hline Escaping training & 1235 & 72.18 & 245 & 75.38 & $1.18(0.90$ to 1.55$)$ \\
\hline Self-defence & 1227 & 71.71 & 257 & 79.08 & $1.48(1.10 \text { to } 2.01)^{\star}$ \\
\hline
\end{tabular}

Han participants as the reference.

${ }^{*} \mathrm{P}<0.05,{ }^{* *} \mathrm{P}<0.01,{ }^{* * \star} \mathrm{P}<0.001$.

WPV, workplace violence.

anxiety is a predisposition to the consequence of WPV occurrence.

Compared with Han, more ethnic minority healthcare professionals pretend nothing happened after suffering from physical violence. In addition, they may be less likely to talk to others about these events, or report to their leaders or use legal methods. The reason why we think there was no statistical significance in this result was that the number of participants who experienced physical violence was small. Despite this, we speculate that this may be due to the cultural beliefs of ethnic minority, causing them to remain silent. A previous study has proved that talking with others in their surroundings about WPV was helpful in releasing the tension or anxiety caused by WPV. ${ }^{38}$ Since anxiety towards WPV is associated with WPV experience, more social support for the individual, such as from friends, families and colleagues, should be provided to help ethnic minority healthcare professionals manage violence through different methods, instead of tolerating WPV by themselves. A previous study has shown that in the environment that encourages reporting of WPV, more incidents of WPV were reported and healthcare workers gained better awareness of the risk of violence, as well as how to avoid potential danger and manage aggressive customers. ${ }^{39}$ An adequate WPV reporting system should be established to encourage ethnic minority healthcare professionals to report their WPV experience.
It seems that both Han and ethnic minority healthcare professionals are less interested in the textual antiviolence training measures (leaflets, poster, wall newspaper, employee handbook). Although printed materials could summarise content and be learnt repeatedly, the lack of practice details makes them less effective. ${ }^{40}$ Videos hold advantages such as attractiveness, convenience, clarity of demonstration, superior cost-effectiveness and easy application, while lectures contain a variety of lively styles such as group interactions and scenario simulations, making them more popular. ${ }^{41}{ }^{42}$ Future studies should compare the effect of these measures. Prejob training is more needed by ethnic minority healthcare workers, which could help them adapt to the work environment better and faster. As for the training content, ethnic minority healthcare professionals are more interested in tough measures. Since ethnic minorities are more likely to suffer from psychological violence, they may perceive more threat and thus give rise to the tendency of handling violence by force. ${ }^{434}$

Our findings indicated that there was not much difference in the evaluation of the usefulness of WPV intervention between Han and ethnic minorities. Security measures are regarded as the most useful intervention for WPV. China has enacted the 'Guidance on strengthening the security and protection system construction in hospitals' in 2013, and the 'Opinions on strictly punishing medical 
Table 5 Evaluation of the usefulness of WPV interventions $(\mathrm{N}=2036)$

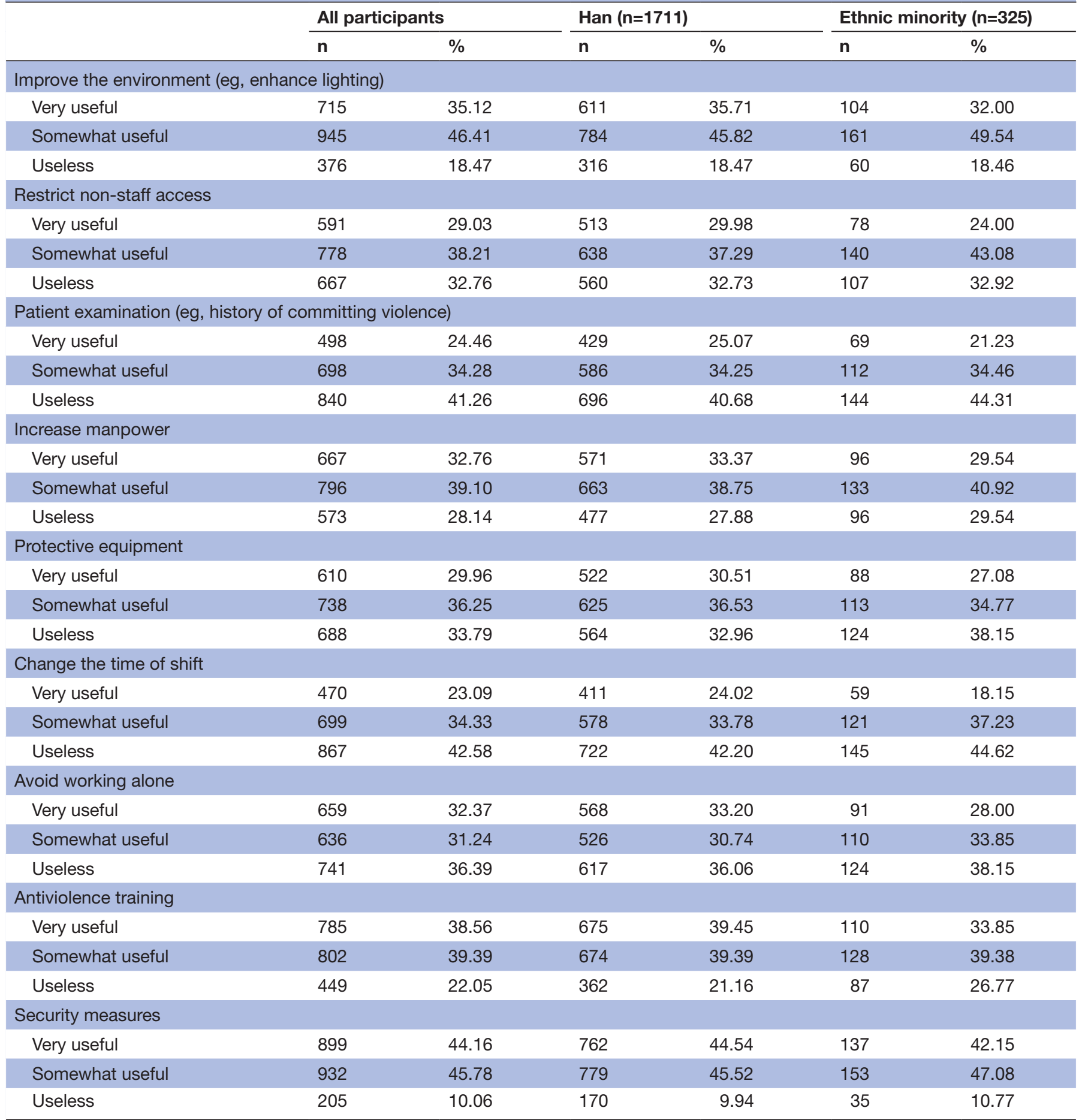

WPV, workplace violence.

related crimes and maintaining the medical order' in 2017, to strengthen hospital security. However, since these policies served as instructions rather than mandatory regulations, insufficient resource had constrained their implementation in all hospitals. Security measures are not only an intervention that could prevent healthcare professionals against WPV, but may also enhance sense of safety as a kind of organisational support.
Hospitals should implement specific scales of security measures according to the actual situation. Most participants considered antiviolence training useful. Although it could increase knowledge and boost confidence, it could not reduce WPV incidents in the long term. ${ }^{45}$ We suggest that it is essential to provide a complete and periodic curriculum for repetitive training. Improving environment, such as enhancing lighting and installing cameras, 
should be considered a useful measure. A previous study has shown that working in a daring environment at night is a risk factor for WPV. ${ }^{46}$ Camera installation is required by the Occupational Safety and Health Administration ${ }^{47}$ and may serve as a deterrence for committing violence. Using protective equipment is not a popular intervention. In the period of frequent WPV in China, there are indeed some healthcare workers wearing a helmet at work. ${ }^{48}$ However, this may lead to a more tense doctorpatient relationship. Participants do not trust patient examinations and restrictions in non-staff access. Due to the large treamtent numbers of this hospital, there would be numerous patients admitted to hospitals. The process of patient examinations and restrictions in nonstaff access should not be too serious, otherwise crowded queues and longer waiting time may breed new contradictions. In addition, since there is no system or platform that shares patient information between hospitals, it is difficult to verify WPV history strictly. Although previous studies have shown that work shift is negatively associated with WPV, ${ }^{19} 3335$ changing the time of shift is treated as less useful. It may be better to enhance protection during shift rather than changing shift regulation.

According to research purpose and background, most previous studies on WPV were conducted in several hospitals, which has several advantages. First, more samples could be collected, providing a more reliable conclusion. In addition, the results could reflect common problems in certain contexts. However, at the same time, it would neglect some specific factors or characteristics. The investigation conducted in a typical and representative hospital is conducive to examining the relation between specific factors or information and WPV, which could also be an effective reference for practical work in hospitals with similar features. Our study has exploratively examined WPV in a multiethnic area using PSM, a method that is conducive to controlling for confounders and minimising the bias caused by quantity gap. As a cross-sectional study, the causal conclusion on ethnicity and gender could be strengthened by this temporality. In addition, our study has provided a complete report about WPV, including prevalence, influencing factors, healthcare professionals' response to WPV, expected content and measure of antiviolence training, and healthcare professionals' evaluation of WPV interventions, which were helpful in interpreting WPV from a wider aspect.

\section{Limitations}

This study has a few limitations. First, since the respondents were asked to report WPV that had taken place in the past 12 months, violence might not be adequately reported due to recall bias or reporting bias resulting from shame and stigma. Second, the study exploratively examined WPV in a multiethnic area but did not conduct indepth research on the underlying cause due to cultural factors. Third, our study is limited to consider the temporality between the influencing factor and WPV, making it difficult to conclude on causation. In addition, the clustering effect of WPV in several departments was not fully considered, which may affect the standard error of the results. Future research should investigate the perpetrators or the patients, and especially explore WPV using qualitative methods.

\section{CONCLUSION}

Our study investigated WPV in a hospital located in a multiethnic area. Ethnic minority healthcare professionals may be more likely to suffer from WPV and have different responses to WPV compared with Han. Additionally, we broke through the single focus of existing WPV research and explored WPV from a more comprehensive perspective, including prevalence, influencing factors, response to WPV, expected antiviolence training measures and content, and evaluation of interventions, which may provide a practical reference to hospitals with similar characteristics. Moreover, WPV research should be conducted in multiethnic areas from the perspective of the perpetrator or the patient, especially using qualitative methods.

\section{Author affiliations}

${ }^{1}$ Department of Medical Affairs, The First Affiliated Hospital, Sun Yat-sen University, Guangzhou, China

${ }^{2}$ Department of Health Policy and Hospital Management, Harbin Medical University, Harbin, Heilongjiang, China

${ }^{3}$ President's Office, Qingdao Women and Children's Hospital, Qingdao, Shandong, China

${ }^{4}$ Department of Human Resources, The First Affiliated Hospital, Sun Yat-sen University, Guangzhou, China

${ }^{5}$ Institue of Quantitative \& Technological Economics, Chinese Academy of Social Sciences, Chaoyang District, Beijing, China

${ }^{6}$ Medical Department, General Hospital of Heilongjiang Agricultural Reclamation, Harbin, Heilongjiang, China

${ }^{7}$ Department of Cardiology, No 1 People's Hospital of Heihe, Heihe, Heilongjiang, China

${ }^{8}$ Department of General Surgery, No 1 People's Hospital of Heihe, Heihe, Heilongjiang, China

${ }^{9}$ Department of Human Resource Management, Harbin Medical University, Harbin, Heilongjiang, China

${ }^{10}$ Department of Social Medicine, Harbin Medical University, Harbin, Heilongjiang, China

Acknowledgements We thank the management office and all the participants for data collection.

Contributors MJ, JM and QW contributed to the conception and design of the study. HJ, HF, YiW, KJ, YL, YaW, LW and GZ contributed to data collection. OYI, HJ and $\mathrm{XJ}$ contributed to literature search and data quality control. HF, HJ and RC did the statistical analysis and drafted the original manuscript. MJ revised the manuscript for important intellectual content. RC, KJ and JL prepared the manuscript. All authors contributed to data interpretation and rewriting the paper.

Funding This study was funded by the Natural Science Foundation of China (grant no. 71273002, 71473064); New Century Excellent Talents of University from the Ministry of Education, China (grant no. 1252-NCET02); the China Postdoctoral Science Foundation (grant no. 2015M570211, 2016T90181); the Heilongjiang Provincial Association of Social Sciences (grant no. 15058); the Collaborative Innovation Centre of Social Risks Governance in Health; and Think Tank of Public Health Security and Health Reform of Heilongjiang Province.

Competing interests None declared.

Patient consent for publication Not required.

Ethics approval This study was reviewed and approved by the Research Ethics Committee of Harbin Medical University and the investigation hospital (project identification code: HMUIRB20160014). 
Provenance and peer review Not commissioned; externally peer reviewed.

Data availability statement Data are available upon reasonable request from the corresponding author and investigation hospital.

Open access This is an open access article distributed in accordance with the Creative Commons Attribution Non Commercial (CC BY-NC 4.0) license, which permits others to distribute, remix, adapt, build upon this work non-commercially, and license their derivative works on different terms, provided the original work is properly cited, appropriate credit is given, any changes made indicated, and the use is non-commercial. See: http://creativecommons.org/licenses/by-nc/4.0/.

\section{ORCID iDs}

Haonan Jia http://orcid.org/0000-0002-8082-1030

Mingli Jiao http://orcid.org/0000-0001-7405-5571

\section{REFERENCES}

1 WHO. Framework guidelines for addressing workplace violence in the health sector. Geneva, Switzerland, 2002.

2 Zhao M, Jiang K, Yang L, et al. The big data research on violence against doctors: based on the media report from 2000 to 2015. Medicine \& Philosophy 2017;38:89-93.

3 Liqun Y, Shoufang J, Xiaoxia T, et al. Analysis of prevalence of workplace violence in staff of two hospitals in Tangshan. Modern Preventive Medicine 2006;33:147-52.

4 Jing G, Pei H, Xiaoli Z, et al. The investigation on coping capacity of nursing staff to medical workplace violence. Chinese Nursing Management 2015;15:688-91.

5 Lin H, Yan J, Jian W, et al. A survey on effect of workplace violence in hospital on work-related stress of medical staffs. Chongqing Medicine 2012;41:590-2.

6 Chen Z-H, Wang S-Y, Jing C-X, et al. [Prevalence of workplace violence in staff of two hospitals in Guangzhou]. Zhonghua Yu Fang Yi Xue Za Zhi 2003;37:358.

7 Liu H, Zhao S, Jiao M, et al. Extent, nature, and risk factors of workplace violence in public tertiary hospitals in China: a crosssectional survey. Int J Environ Res Public Health 2015;12:6801-17.

8 Zhao S, Liu H, Ma H, et al. Coping with workplace violence in healthcare settings: social support and strategies. Int J Environ Res Public Health 2015;12:14429-44.

9 Coate S, Loury GC. Will Affirmative-Action policies eliminate negative stereotypes? The American Economic Review 1993;83:1220-40.

10 Hasmath R, Ho B. Job acquisition, retention, and outcomes for ethnic minorities in urban China. Eurasian Geogr Econ 2015;56:24-43.

11 Chinese medical doctor association. White paper on medical practice in China, 2017.

$12 \mathrm{Ji} \mathrm{H}$, Tian K, Yunsen Z. Studying on the guarantee of medical professionals' right of rest and construction of harmonious doctorpatient relationship. The Chinese Health Service Management 2016;33:368-70.

13 Tak S, Sweeney MH, Alterman T, et al. Workplace assaults on nursing assistants in US nursing homes: a multilevel analysis. Am J Public Health 2010;100:1938-45.

14 Cai W, Deng L, Liu M, et al. Antecedents of medical workplace violence in South China. J Interpers Violence 2011;26:312-27.

15 Liu Y, Deng L, Min Y. Investigation of psychological violence at hospital workplace in Guangzhou. Chinese Journal of Public Health 2009;25:1050-1.

16 Qianqian W, Lei X. Investigation of workplace violence and influencing factors of nurses in Pingyang County General Hospital. J Tradit Chin Med 2016;24:18-20.

17 Lulu S. The research of prevention of hospital workplace violence based on game theory - through the analysis of hospital, patient, and media as game role players. Jilin University, 2014.

18 Jiao M, Ning N, Li Y, et al. Workplace violence against nurses in Chinese hospitals: a cross-sectional survey. BMJ Open 2015;5:e006719.

19 Sun P, Zhang X, Sun Y, et al. Workplace violence against health care workers in North Chinese hospitals: a cross-sectional survey. Int $J$ Environ Res Public Health 2017;14:96.

20 Miedema B, Hamilton R, Lambert-Lanning A, Baukje M, Ryan H, Anita LL, et al. Prevalence of abusive encounters in the workplace of family physicians: a minor, major, or severe problem? Can Fam Physician 2010;56:e101.

21 Campbell JC, Messing JT, Kub J, et al. Workplace violence: prevalence and risk factors in the safe at work study. J Occup Environ Med 2011;53:82.
22 Quine L, Lyn Q. Workplace bullying in junior doctors: questionnaire survey. BMJ 2002;324:878-9.

23 Jane B, Geoff P. At breaking point: a survey of the wellbeing and working lives of nurses in 2005. London, England: Royal College of Nursing, 2006.

24 Giga SI, Hoel H, Lewis D. A review of black and minority ethnic (BME) employee experiences of workplace bullying, 2008.

25 Keshet Y, Popper-Giveon A. Race-based experiences of ethnic minority health professionals: Arab physicians and nurses in Israeli public healthcare organizations. Ethn Health 2018;23:442-59.

26 Dehghan-Chaloshtari S, Ghodousi A. Factors and characteristics of workplace violence against nurses: a study in Iran. J Interpers Violence 2020;35:496-509.

27 Kang C. Cultural differences between Tibetans and ethnic Han Chinese in ultimatum bargaining experiments. J Political Econ 2009;25:78-84.

28 Perloff RM, Bonder B, Ray GB, et al. Doctor-Patient communication, cultural competence, and minority health: theoretical and empirical perspectives. American Behavioral Scientist 2006;49:835-52.

29 Beech B, Leather P. Workplace violence in the health care sector: a review of staff training and integration of training evaluation models. Aggress Violent Behav 2006;11:27-43.

30 Hahn S, Zeller A, Needham I, et al. Patient and visitor violence in general hospitals: a systematic review of the literature. Aggress Violent Behav 2008;13:431-41.

31 Wu S, Zhu W, Li H, et al. Workplace violence and influencing factors among medical professionals in China. Am J Ind Med 2012;55:1000-8.

32 Algwaiz WM, Alghanim SA. Violence exposure among health care professionals in Saudi public hospitals. A preliminary investigation. Saudi Med J 2012;33:76.

33 Carluccio A, Knychala V, Marshall C. Violence against frontline NHS staff. London: NHS Security Management Service, 2010.

34 Flannery RB, Walker AP. Characteristics of four types of patient assaults: six year analysis of the Assaulted staff action program (ASAP). Psychiatric Quarterly 2011;82:11-21.

35 Kitaneh M, Hamdan M. Workplace violence against physicians and nurses in Palestinian public hospitals: a cross-sectional study. BMC Health Serv Res 2012;12:1-9.

36 Arimatsu M, Wada K, Yoshikawa T, et al. An epidemiological study of work-related violence experienced by physicians who graduated from a medical school in Japan. J Occup Health 2008;50:357-61.

37 Hills D, Joyce C. A review of research on the prevalence, antecedents, consequences and prevention of workplace aggression in clinical medical practice. Aggress Violent Behav 2013;18:554-69.

38 Coker AL, Smith PH, Thompson MP, et al. Social support protects against the negative effects of partner violence on mental health. $J$ Womens Health Gend Based Med 2002;11:465-76.

39 Arnetz JE, Arnetz BB. Implementation and evaluation of a practical intervention programme for dealing with violence towards health care workers. J Adv Nurs 2000;31:668-80.

40 Ramezaninia J, Naghibi Sistani MM, Ahangari Z, et al. Comparison of the effect of toothbrushing education via video, lecture and pamphlet on the dental plaque index of 12-year-old children. Children 2018:5:50.

41 Li F, Jiang F, Jin X-M, et al. Cost-efficiency assessment of 3 different pediatric first-aid training models for caregivers and teachers in Shanghai. Pediatr Emerg Care 2011;27:357-60.

42 Lees A, Rock WP. A comparison between written, verbal, and videotape oral hygiene instruction for patients with fixed appliances. J Orthod 2000;27:323-8.

43 Meloy JR. Pathologies of attachment, violence, and criminality. In: Handbook of Psychology, 2003: 509-26.

44 Meloy JR. The psychopathic mind: origins, dynamics, and treatment. Rowman \& Littlefield, 1988.

45 Heckemann B, Zeller A, Hahn S, et al. The effect of aggression management training programmes for nursing staff and students working in an acute hospital setting. A narrative review of current literature. Nurse Educ Today 2015;35:212-9.

46 Simonowitz JA, Rigdon JE, Mannings J, et al. Workplace violence. prevention efforts by the occupational health nurse. Aaohn $J$ 1997;45:305-18

47 Occupational Safety Health Administration. Guidelines for preventing workplace violence for health care social service workers. Occupational Safety Health Administration, 2004.

48 Sina. Healthcare workers wear helmets to work for safety: sina; 2006. Available: http://news.sina.com.cn/s/p/2006-12-25/ 064711876752.shtml2006 